\title{
PAISAJES PRODUCTIVOS ACTUALES Y PASADOS EN EL SECTOR NORTE DE LA QUEBRADA DE HUMAHUACA
}

\author{
Juan Bautista Leoni ${ }^{1}$ y Giorgina Fabron ${ }^{2}$
}

Recibido: 8 de julio de 2017. Aceptado: 2 de octubre de 2017

\begin{abstract}
Resumen
En este trabajo se aborda la conformación de paisajes agrícolas en una parte del sector norte de la Quebrada de Humahuaca, un área donde el desarrollo de la agricultura está condicionado por las rigurosas condiciones ambientales que la caracterizan. Empleando técnicas de análisis espacial, se realiza una caracterización general de la estructura y organización espacial del asentamiento y de la producción agrícola actual, describiendo las formas de ocupación densa y dispersa que se evidencian en la zona. Luego, se discuten las evidencias arqueológicas disponibles de los paisajes productivos pretéritos, en especial el sitio arqueológico Antumpa. A pesar que la información para estos últimos es todavía muy fragmentaria, se realiza una comparación con la estructura espacial del asentamiento actual, identificándose instancias de continuidad a largo plazo en el uso del espacio productivo. Se señalan también posibles evidencias de cambios significativos, que se manifiestan sobre todo en el emplazamiento de las instalaciones agrícolas arqueológicas en cotas elevadas. Esto podría reflejar tanto la expansión de la capacidad productiva de la zona en ciertos momentos del pasado como también condiciones ambientales diferentes a las actuales que harian posible el cultivo en esos lugares.
\end{abstract}

Palabras clave: paisajes productivos, Quebrada de Humahuaca, asentamiento, análisis espacial, Antumpa.

\begin{abstract}
In this paper we discuss the conformation of agricultural productive landscapes in a part of the Northern sector of the Humahuaca Quebrada. This is an area where agricultural production is hampered by to the rigorous environmental conditions that characterize it. By employing spatial analysis techniques, we characterize the general spatial structure and organization of current day settlement and agricultural production, focusing on the dense and disperse occupation patterns that can be discerned in the area. Then, we discuss the available archaeological evidences for past productive landscapes, with special attention paid to the Antumpa archaeological site. Even when the information of past productive landscapes is still fragmentary, we compare the available data with the spatial patterns of the modern settlement structure, identifying instances of long term continuity in the use of productive spaces. We point out possible evidences of significant changes as well, as represented by the emplacement of archaeological agricultural facilities on higher elevations. This could reflect both the intention to expand the area's productive potential in certain times in the past, as well as different environmental conditions that made cultivation in those places possible.

Key words: productive landscapes, Humahuaca Quebrada, settlement, spatial analysis, Antumpa
\end{abstract}

1 CONICET - Departamento de Arqueología, Escuela de Antropología, Facultad de Humanidades y Artes, Universidad Nacional de Rosario; Entre Ríos 758, 2do Piso, (2000) Rosario, Santa Fe; E-mail: jbleoni@hotmail.com

2 CONICET - Instituto de Arqueología, Facultad de Filosofia y Letras, Universidad de Buenos Aires; 25 de mayo 217/221, 3er piso, (1002), Ciudad Autónoma de Buenos; E-mail: giorgina_fabron@ hotmail.com 


\section{Introducción}

Este trabajo aborda la conformación de paisajes agrícolas en una parte del sector norte de la Quebrada de Humahuaca. Las condiciones ambientales que la caracterizan actúan como factores limitantes para el desarrollo de la agricultura, restringiéndola a ciertas áreas. Nuestra investigación arqueológica en la zona ha permitido constatar que extensiones importantes de estructuras prehispánicas de probable uso agrícola se emplazan en lugares que hoy no se encuentran habitados ni son aprovechados para el cultivo. Asimismo, los instrumentos líticos de uso agrícola (palas/azadas) se destacan en los conjuntos artefactuales recuperados en las excavaciones desarrolladas en Antumpa, el principal sitio arqueológico de la zona. Estas características del registro arqueológico evidenciarian que la práctica agrícola tuvo cierta preponderancia en el pasado, presumiblemente mayor que en la actualidad. Situaciones similares han sido observadas en otras partes del noroeste argentino (NOA) (e.g. González 2011; Ottonello y Ruthsatz 1986; Zuccarelli 2014; entre muchos otros) y suelen atribuirse a la profunda desarticulación sociocultural producida por la conquista europea. Ciertas características que se observan en la zona aquí analizada, tales como diferencias de emplazamiento entre las áreas agrícolas actuales y pasadas, sugieren que factores de tipo ambiental también podrian haber incidido en la conformación diferencial de los paisajes agrarios a través del tiempo.

En función de esta problemática, el trabajo busca abordar el estudio de los paisajes productivos actuales y pasados, tomando como muestra analítica un área del sector norte de la Quebrada de Humahuaca definida operativamente en torno al sitio arqueológico Antumpa. Se emplea un conjunto de técnicas de análisis espacial de uso corriente en arqueología con el fin de avanzar hacia una comparación sistemática entre la estructura y organización espacial del asentamiento y de la producción agrícola actual, y las que caracterizaron a las sociedades que habitaron la zona en el pasado, aunque para estas últimas la información es todavía muy fragmentaria. De esta manera se busca determinar si existen instancias de continuidad a largo plazo en el uso del espacio productivo o si, por el contrario, se evidencian cambios significativos. Los resultados aquí presentados constituyen una caracterización general y de grano grueso de los paisajes productivos, que deberán profundizarse en el futuro con el uso de técnicas más específicas.

\section{Consideraciones teóricas}

Este trabajo se enmarca en la perspectiva de análisis que se conoce en términos amplios como arqueología del paisaje. Dentro de esta perspectiva, la arqueología se entiende fundamentalmente como el análisis de la cultura material y de la modificación humana de los espacios, lo que redunda en que un enfoque arqueológico pueda ser viable tanto para el estudio de configuraciones espaciales pasadas como actuales, así como de la trayectoria diacrónica que las conecta. Lejos de ser un simple escenario pasivo para el desarrollo de las actividades humanas, el paisaje cultural juega un rol activo, a la vez estructurado por y estructurante de la agencia humana (Acuto 2013; Ballesteros Arias y Criado Boado 2009; Criado Boado 1991; David y Thomas 2008; Strang 2008; Tello 1999; entre otros).

La perspectiva del paisaje tiene gran potencial para el estudio de las formas de construir y gestionar los espacios productivos agrícolas presentes y pretéritos. Como Clark Erickson (2006:350) ha señalado, los paisajes agrícolas constituyen el 
fruto del trabajo campesino de múltiples generaciones, a lo largo de lapsos de tiempo prolongados. Como tales, implican inversiones sostenidas de capital y trabajo que han dejado una marca perenne en el entorno fisico, y que a su vez condicionan y canalizan los movimientos y actividades de las generaciones posteriores. Estos paisajes agricolas materializan las relaciones sociales y productivas bajo las cuales se construyeron y utilizaron (Erickson 2000, 2006; Quesada 2006; Tello 1999). De esta forma, como sostiene Enric Tello (1999: 197), un paisaje agrícola determinado suele registrar, a la manera de un palimpsesto, las sucesivas huellas territoriales y tecnológicas de las sociedades y paisajes que le precedieron en el tiempo.

Entendemos que el estudio de las formas de estructuración y uso de los espacios productivos actuales en el sector norte de la Quebrada de Humahuaca puede resultar de gran valor para entender el extenso proceso histórico por el que las sociedades pre- y post-hispánicas modificaron y configuraron el entorno físico, imprimiéndole una huella cultural. Idealmente, esta "arqueología del paisaje tradicional" (sensu Ballesteros Arias y Criado Boado 2009: 601) permite comprender mejor la forma en que los grupos humanos modelaron su entorno físico-ambiental durante siglos, detectando instancias de cambio y de continuidad, momentos de expansión y de retracción de la infraestructura productiva, así como potenciales variaciones en el entorno ambiental y las respuestas socioculturales implementadas frente a ello. Es decir, siguiendo a Ballesteros Arias y Criado Boado (2009: 600), “(...) partimos de la observación del paisaje para poder hacer una retrospectiva hacia su génesis $\mathrm{y}$ formación".

\section{Escala de análisis espacial y caracteristicas ambientales actuales y pasadas}

El área de estudio se ha definido operativamente, abarcando una parte del sector norte de la Quebrada de Humahuaca que muestra concentración de población en la actualidad y que parece haber nucleado población también en tiempos prehispánicos. Se trata de un área relativamente pequeña, con una superficie de $59 \mathrm{~km}^{2}$, aunque variada en su geomorfología y ocupación humana actual. Incluye el fondo de la Quebrada de Humahuaca, desde el extremo oeste del paraje Negra Muerta, la población de Hipólito Yrigoyen (o Iturbe), la curva del río Grande hacia el sur, donde se ubica el sitio arqueológico Antumpa, y un tramo de la quebrada del río Grande de aproximadamente $1.550 \mathrm{~m}$ desde Antumpa hacia el sur (Figura 1). El área incluye la desembocadura de las quebradas de La Cueva, Moldes, Chaupi Rodeo y Charcomayoc en la margen izquierda del río Grande, varias quebradas pequeñas y hondonadas que desembocan en la margen derecha de este río, así como amplias zonas elevadas de interfluvios. ${ }^{1}$

En términos de altitud, el fondo de la Quebrada de Humahuaca oscila en este sector entre los 3.300 y 3.450 msnm. Los tramos inferiores de las quebradas tributarias por la margen izquierda presentan alturas semejantes, en tanto las zonas elevadas entre ellas alcanzan los 3.500-3.600 msnm. El territorio ubicado sobre la margen derecha del río Grande, por su parte, se ubica entre los 3.400 y $3.600 \mathrm{msnm}$.

El clima actual en la región es frío y seco en invierno, y cálido y seco en verano, aunque con gran amplitud térmica diaria (Buitrago y Larran 1994). Las precipitaciones son estivales y torrenciales, producto de vientos húmedos provenientes del norte y del este, registrando la población de Hipólito Yrigoyen un promedio de $252 \mathrm{~mm}$ de 


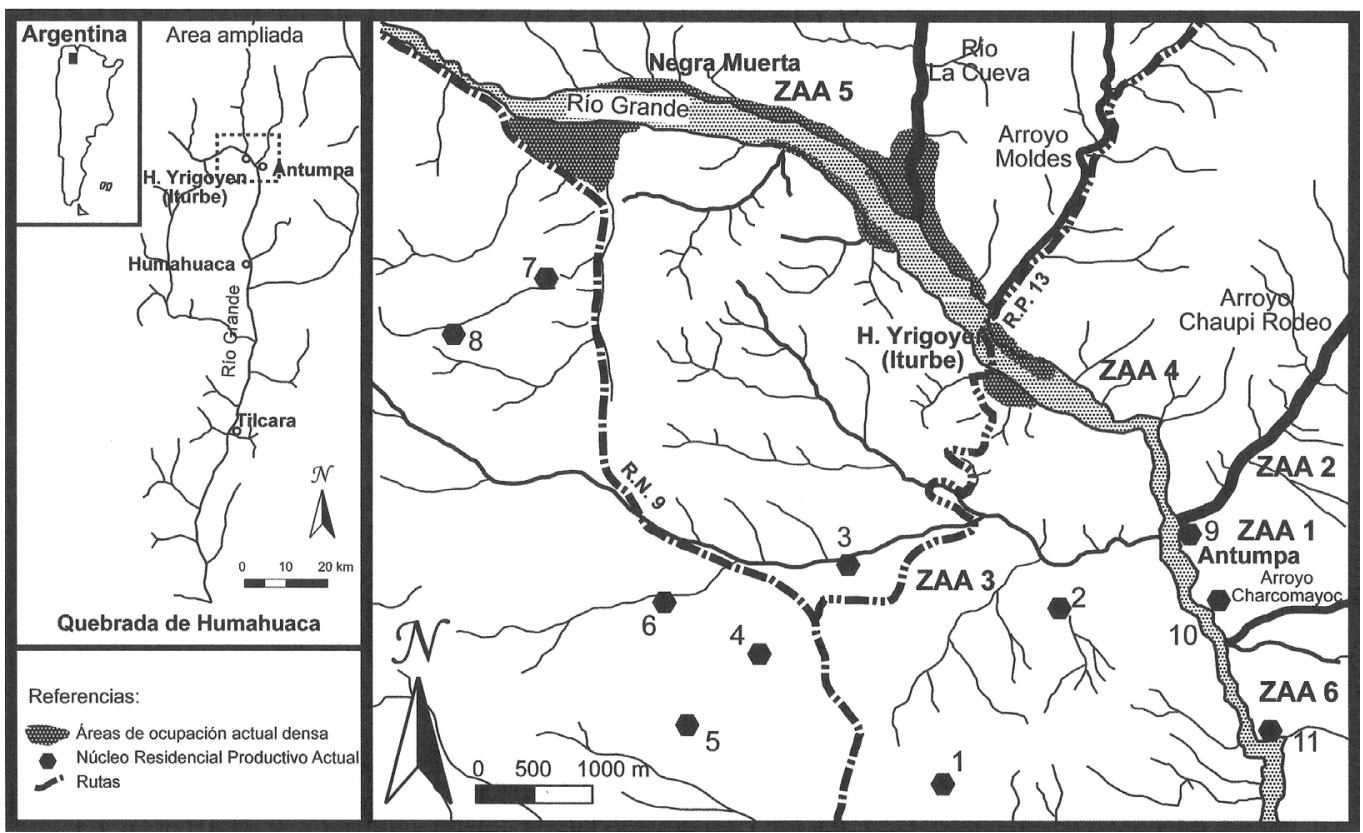

Figura 1. Mapa del área de estudio.

lluvias anuales desde mediados del siglo XX (Bianchi y Yáñez 1992). ${ }^{2}$ Esto es, un valor anual superior a los que se presentan en el sector medio de la Quebrada de Humahuaca (136 mm para Tilcara, $175 \mathrm{~mm}$ para Humahuaca), lo que es motivado por la mayor elevación del fondo de la quebrada en este sector con respecto a las cadenas que forman su borde oriental, factor que facilita la penetración de los vientos húmedos del este (Madrazo 1969: 10). Las heladas son frecuentes en invierno.

El curso de agua más importante en la zona es el río Grande. Su flujo en esta zona es permanente durante el ciclo anual, pero en ciertos períodos y lugares el agua se infiltra llegando a desaparecer del nivel superficial. Los aportes que recibe de los distintos tributarios (La Cueva, Moldes, Chaupi Rodeo) son escasos (Paoli 2003). Por otra parte, la mayor parte de las quebradas de menor tamaño que se encuen- tran en el área de estudio sólo presentan agua en el verano, fruto de las lluvias y del incremento del deshielo. Una fuente adicional de agua permanente está dada por surgentes y manantiales, que dan origen a pequeñas vegas distribuidas por toda el área considerada.

En términos fitogeográficos, se encuentran representadas en el área bajo estudio las Provincias Prepuneña y Puneña (ver Ruthsatz y Movia 1975). La primera de ellas corresponde a las partes del área ubicadas por debajo de los $3.400 \mathrm{msnm}$; es decir, el fondo de la Quebrada de Humahuaca y los tramos inferiores de las quebradas tributarias por su margen izquierda. La Provincia Puneña, por su parte, se presenta entre los 3.400 y $4.000 \mathrm{msnm}$, comprendiendo en el área bajo estudio las zonas elevadas entre las quebradas tributarias por la margen izquierda del río Grande y prácticamente todo el territorio 
ubicado sobre su margen derecha. En relación a la fauna, corresponde al Dominio Andino (Ringuelet 1961), aunque en la actualidad la mayoría de sus representantes (e.g. tarucas, guanacos y vicuñas, zorros y pumas, etc.) son poco comunes en la zona.

Los estudios paleoambientales específicos para esta zona o áreas cercanas son aún escasos, aunque tienden a dar cuenta de transformaciones en las condiciones de sedimentación y erosión en diversos momentos en el pasado, posiblemente reflejando variaciones en las condiciones climáticas. Así, el estudio de las barrancas del río Grande en Esquinas Blancas, a corta distancia hacia el oeste de Hipólito Yrigoyen, por Jorge Fernández (1984), determinó que la acumulación de sedimentos finos estratificados intercalados con estratos de turba y materia orgánica que forma las mismas resulta incongruente con el régimen hidrológico actual del río Grande. En función de ello dedujo que debía reflejar condiciones climáticas diferentes en el pasado. Mediante el fechado radiocarbónico de los estratos de turba y materia orgánica planteó que entre 5000 y 2000 a.p. el agua no circulaba con fuerza como en la actualidad y que el fondo del cauce presentaba un encenagamiento, así como la inexistencia de crecientes estacionales como las actuales. Atribuyó hipotéticamente estas diferencias a la existencia de un régimen pluvial con precipitaciones más distribuidas a lo largo del ciclo anual.

Por su parte, los trabajos de Julio Kulemeyer $(2005,2013)$ en la cuenca del río Yavi también indican variaciones climáticas y morfodinámicas durante el Holoceno Tardío en la región, comenzando a darse un cambio hacia las condiciones actuales a partir de 2000/1500 a.p. Al igual que Fernández, identifica un cese de la acumulación de sedimentos y un incremento de la incisión de los valles a partir de este momento y sugiere que prácticas culturales como el pastoreo y la agricultu- ra habrian contribuido a la reducción de la cubierta vegetal y al aumento del escurrimiento y erosión superficial. Así, la creciente presión antrópica habría generado cambios en los suelos, la vegetación y la dinámica hídrica, intensificándose los procesos de erosión y acumulación (Kulemeyer 2005, 2013).

Finalmente, el estudio geoarqueológico de Antumpa por Gabriel Cortés (2013) confirma que hacia el 1800 a.p. se habria desarrollado una fase de erosión regional que predomina hasta la actualidad y durante la cual los ríos y arroyos alcanzarían el carácter torrencial actual. Con posterioridad a 1350 a.p. los depósitos corresponden a eventos episódicos de crecidas (arenas gruesas, gravas y bloques). Entre 480-500 a.p. se produce el último proceso de acumulación aluvial y con posterioridad a esta fecha continuaría la incisión de este sector de la cuenca alta del río Grande.

En suma, si bien los estudios paleoambientales específicos para la zona o sus adyacencias son aún escasos, apuntan a la existencia de transformaciones en las condiciones ambientales en el Holoceno Tardío (algo que también plantean otros estudios de carácter más regional; ver más abajo), con cambios en las condiciones climáticas y geodinámicas, así como el impacto creciente de las actividades humanas en el paisaje.

\section{Aspectos generales de las actividades productivas actuales}

La ocupación humana actual del área estudiada se concentra principalmente en las poblaciones de Hipólito Yrigoyen y Negra Muerta, en forma concentrada y urbanizada en el primer caso, y en forma más dispersa a lo largo del fondo de la quebrada en el segundo (Figura 1). La población permanente se dedica sobre todo a la agricultura y ganadería a pequeña escala. In- 
gresos extraprediales como empleo público, trabajo en zonas urbanas o empresas mineras, comercio, subsidios, programas asistenciales y jubilaciones son las fuentes principales de ingreso monetario. Numerosas viviendas y puestos abandonados testimonian un proceso de despoblamiento y de expulsión de la población hacia otras regiones más activas económicamente (en Jujuy u otras provincias), proceso agudizado en tiempos recientes (ver Bidaseca 2013; Golovanevsky y Ramírez 2014; entre otros). En efecto, el Censo Nacional 2001 registró 1.285 personas para toda el área de la Comisión Municipal de Hipólito Yrigoyen (que incluye también poblaciones como La Cueva, Miyuyoc y Chaupi Rodeo, fuera de la zona aquí considerada), en tanto en 2010 la población del mismo distrito totalizaba sólo 1.013 habitantes.

Es interesante destacar que Negra Muerta fue una de las haciendas más grandes dentro del Departamento Humahuaca durante el siglo XIX y principios del siglo $X X$. Encuentra sus orígenes en una serie de cesiones de tierra realizadas durante la colonia (Fandos 2014) y ha sido caracterizada como "una hacienda de arrendatarios" (sensu Madrazo 1982, citado en Fandos 2014: 48). Hacia 1864 “(...) en esta propiedad se albergaba al $31 \%$ del total de la población departamental" (Fandos 2014: 49). Esta preeminencia demográfica tenía un correlato económico, al representar su stock ganadero (11 vacunos, 105 caballos, 1.060 burros y 15.500 ovinos) el 22\% del total del capital departamental por ganado y el $10 \%$ de la suma global de riqueza en la zona (Fandos 2014: 49). A comienzos del siglo XX, Negra Muerta todavía presentaba las características de un latifundio, consignándose en su haber más de 300 arriendos (Karasik 2008-09: 211).

La ganadería y la agricultura que se practican en la zona en la actualidad son de pequeña escala, realizadas por grupos familiares y dirigidas sobre todo a la auto- subsistencia y al intercambio o venta limitados. La primera es de tipo extensivo, en base a pastizales naturales e incluye la cría de ganado vacuno, equino, caprino y ovino, en pequeñas cantidades (ver Forgione 1982, para un estudio etnográfico detallado de la actividad pastoril en la Quebrada de Chaupi Rodeo). Recientemente se ha introducido también un pequeño rebaño de llamas en las afueras de Hipólito Yrigoyen.

La agricultura, por su parte, se ve condicionada por las condiciones ambientales locales. La altitud sobre el nivel del mar, la marcada amplitud térmica diaria, los distintos procesos de erosión (eólica e hídrica) característicos de la zona y las condiciones edáficas (escaso desarrollo pedológico, bajo contenido de materia orgánica de los suelos), actúan como factores limitantes. En general, son los cultivos microtérmicos nativos, resistentes al frío y la altura los que mejor se adaptan a esta zona, que forma parte de lo que Albeck (1992-93: 66) define como "áreas agrícolas elevadas". ${ }^{3}$ Éstas comprenden áreas pedemontanas elevadas, faldeos montañosos y partes altas de quebradas laterales con presencia de agua y suelos adecuados. El curso del río Grande en esta zona queda incluido también en esta caracterización, debido a la gran altura sobre el nivel del mar que presenta (Albeck 1992-93:68).

Se practica el cultivo con riego (y en algunos casos también "al tiempo"4) y, en términos generales, queda limitado al período primavera-verano. La siembra se efectúa en octubre (en algunos años en septiembre) y la cosecha, dependiendo del cultivo, hacia marzo-junio. Los cultivos incluyen un amplio rango de especies vegetales, tanto locales (e.g. quinua, oca, papa tuna, maíz), como introducidas a partir la conquista española (e.g. arvejas, zanahorias, habas y cebollas), asi como árboles frutales (e.g. duraznos y manzanas). E1 maíz actualmente se cultiva con poca frecuencia en la zona, siendo las variedades 
más sembradas las conocidas localmente como "tipo bolita" y "ocho rayas" (Fabron 2016). Estas variedades son cultivadas cuando los productores consideran que el clima "va presentar las condiciones favorables para su crecimiento" (entrevista a D.G., habitante de Negra Muerta, mayo 2017).

La actividad agrícola se realiza en las cercanías de las unidades residenciales o bien en puestos y parcelas alejados de las mismas. Los espacios de cultivos se localizan por lo general en terrenos ubicados en los fondos de cuenca y también en terrazas fluviales y laderas, en relación directa con los recursos hídricos disponibles (ríos, arroyos, surgentes), siendo muy variables en sus dimensiones y formas. Suelen encontrarse delimitados por muros de piedra, aunque por lo general los cultivos ocupan sólo una pequeña parte de la superficie formalmente delimitada. Este tipo de agricultura se caracteriza por no requerir gran infraestructura, aunque se ha observado la instalación de tubos de plástico, caños y mangueras para optimizar el riego, así como el uso del tractor para las labores de arado en lugares donde el relieve lo permite (Fabron 2014).

\section{Estructura y organización espacial del asentamiento y la producción actual}

\section{Metodologia de análisis}

El objetivo primario del trabajo es obtener una caracterización de grano grueso de la estructura y organización espacial del asentamiento y la producción en la zona, basándonos principalmente en el análisis de imágenes de sensores remotos (imágenes satelitales y aerofotos). Complementamos esto con información recogida por medio de entrevistas y observaciones directas realizadas en el curso de nuestras investigaciones en la zona desde 2007.

Se procedió a localizar la ubicación de las unidades habitacionales y de las áreas productivas actuales y pasadas existentes en el área estudiada, teniendo en cuenta aspectos tales como la altura sobre el nivel del mar, la proximidad a fuentes de agua y la topografía en que se ubican. Se relevó, para los asentamientos actuales, el número y tipo de estructuras presentes, la planta y la superficie de las mismas, diferenciando entre espacios techados, corrales y espacios agrícolas delimitados. Para ello se emplearon las imágenes satelitales incluidas en el programa Google Earth, y en las aplicaciones Google Maps y Bing Maps, de acceso público, así como aerofotos de la Dirección Nacional de Geología y Minería y cartas topográficas del IGM (escala 1:50.000). El cálculo de superficie se realizó mediante la creación de polígonos en el Google Earth, los cuales fueron exportados $\mathrm{y}$ convertidos en shape file y volcados en un SIG, en el cual se realizaron los cálculos necesarios mediante el software Qgis 2.14.2.

Dado que el tamaño de los sitios es una variable clave en los análisis espaciales de patrón de asentamiento en arqueología (e.g. Johnson 1977; Raffino 1991; Willey 1953), nos enfocamos especialmente en obtener mediciones que permitan sistematizar las observaciones y efectuar comparaciones entre asentamientos. Sin embargo, el cálculo de la superficie de un asentamiento puede resultar dificultoso, especialmente en casos como los que presentamos aquí, que suelen mostrar un bajo grado de aglutinamiento y la intercalación de áreas de vivienda, productivas y espacios carentes de construcciones. Ante esto, optamos por considerar la suma de todo el espacio construido (habitaciones, corrales y espacios de cultivo definidos formalmente con pircas), para obtener la superficie total de un asentamiento, excluyendo los espacios entre las construcciones en el cálculo del 
total. Asimismo, calculamos la proporción existente en cada asentamiento entre espacio formalmente delimitado dedicado a la agricultura (chacras, canchones) y al pastoreo (corrales), y el espacio techado (habitaciones, depósitos). Esto nos permite disponer de un parámetro comparativo formal para evaluar las actividades productivas, más preciso que la sola consideración de los valores absolutos de la superficie dedicada a cada actividad.

Se procedió también a la aplicación de la técnica analítica del Análisis de Vecino más Cercano. ${ }^{5}$ Este análisis describe el grado de concentración de un conjunto de puntos en el espacio bidimensional, estimando el promedio de la distancia entre esos puntos y comparándola con la distancia promedio esperada si dicha distribución fuese completamente al azar. Los indices obtenidos permiten, tentativamente, evaluar si la distribución en el espacio es azarosa o si por el contrario muestra tendencias hacia el agrupamiento o la dispersión (Earle 1976; Pinder et al. 1979).

\section{Caracterización espacial de la ocupación actual}

La ocupación humana en el sector seleccionado presenta distintos niveles de aglomeración y densidad de asentamiento. Destaca la diferencia entre zonas con una ocupación densa del espacio y zonas con ocupación más dispersa.

La zona de ocupación que caracterizamos como densa corresponde sobre todo al paraje Negra Muerta y la población de Hipólito Yrigoyen, que conforman una ocupación continua de unos $6 \mathrm{~km}$ de extensión sobre el curso del río Grande (Figura 1). ${ }^{6}$ La construcción de la estación Iturbe del FFCC General Belgrano en 1907 (Ferrari 2014), y posteriormente de la Ruta Provincial 13, introdujo una urbanización y concentración demográfica que clara- mente rompió el patrón de asentamiento preexistente. Muy probablemente, el mismo mostraba una forma de ocupación similar a la que se ve hoy en día en Negra Muerta extendiéndose también en el sector actualmente ocupado por la población de Hipólito Yrigoyen.

El análisis de imágenes satelitales nos permitió identificar para Negra Muerta un total de 122 estructuras techadas, correspondientes en su gran mayoria a habitaciones, generalmente no contiguas entre sí, y 49 estructuras similares en desuso, carentes de techo. Los espacios de cultivo ocupan una superficie substancial, disponiéndose intercaladamente entre las viviendas. El cálculo de la proporción entre la superficie de los espacios de cultivo y la de las estructuras techadas produce un valor de $140,9 \mathrm{~m}^{2}$ de tierras de cultivo por cada metro cuadrado de estructura techada, el valor más alto para toda el área bajo estudio y claramente indicativo de la orientación agraria del asentamiento (Tabla 1). Si bien se registran estructuras vinculadas al pastoreo, la proporción de la superficie de las mismas en relación a la superficie techada es muy baja $\left(1,8 \mathrm{~m}^{2}\right.$ de superficie de corrales por metro cuadrado de estructura techada). Esta caracteristica del asentamiento, junto con el bajo grado de aglutinamiento de las viviendas, determina la gran extensión del mismo, que se correspondería en términos arqueológicos a lo que suele denominarse "poblado disperso" (sensu Madrazo y Ottonello 1966:1112) o "trazado disperso" (Raffino 1991:81). Es interesante, por otra parte, que Negra Muerta no presenta edificios o zonas de uso comunitario ni espacios públicos que actúen como centro sociopolítico, religioso o simbólico del asentamiento. ${ }^{7}$

Por el contrario, la población de $\mathrm{Hi}$ pólito Yrigoyen muestra un alto grado de aglomeración de las viviendas, que se disponen según una grilla tradicional de calles y manzanas en su parte central. A lo 


\begin{tabular}{|l|r|r|r|}
\hline Asentamiento & Sup. construida & cultivo:techada & corral:techada \\
\hline Negra Muerta & 972056 & 140,9 & 1,8 \\
Iturbe & 238678 & 1,7 & ND \\
NRPA 1 & 1742 & 1,04 & 3,8 \\
NRPA 2 & 2141 & 14,5 & 10,3 \\
NRPA 3 & 608 & 1,6 & 1,6 \\
NRPA 4 & 2172 & 3,1 & 8,7 \\
NRPA 5 (a) & 217 & - & 3,9 \\
NRPA 6 (a) & 308 & - & 8,3 \\
NRPA 7 (b) & 171 & 8,5 & - \\
NRPA 8 (c) & 628 & - & - \\
NRPA 9 & 2779 & 12,8 & 13,2 \\
NRPA 10 & 27724 & 254,1 & 8,9 \\
NRPA 11 & 24786 & 167,4 & 4,9 \\
\hline
\end{tabular}

(a) Sin superficies de cultivo definidas

(b) Sin corrales

(c) Sin superficies de cultivo definidas ni corrales

Tabla 1. Proporción entre superficie de cultivo y superficie de corrales por estructuras techadas $\left(\mathrm{m}^{2}\right)$, en los distintos asentamientos analizados.

largo de una calle principal, junto a la estación del FFCC, se disponen la delegación municipal, la capilla, la escuela y algunos comercios. En su periferia pueden encontrarse también algunos espacios de cultivo y corrales. Esta configuración resulta de su diseño original como centro urbanizado, y se refleja en la baja proporción existente entre la superficie de los espacios de cultivo y la de las estructuras techadas, que apenas alcanza 1,7 $\mathrm{m}^{2}$ de tierras de cultivo por cada metro cuadrado de estructura techada (Tabla 1). Aún cuando su extensión total es de apenas la cuarta parte de la de Negra Muerta, la presencia de las instituciones estatales (comisión municipal, escuelas primaria y secundaria), de comercios y de una capilla, así como su emplazamiento junto a la vía del FFCC y la Ruta Provincial 13, le otorgan una mayor significación política y económica, siendo la población más importante de esta parte del sector norte de la Quebrada de Humahuaca.
La ocupación que denominamos dispersa, por su parte, se localiza tanto en sectores puntuales del curso del río Grande ubicados al sureste de Negra Muerta/Hipólito Yrigoyen, como en las áreas elevadas sobre la margen derecha del río Grande, en relación con pequeñas quebradas y fuentes de agua temporales y/o permanentes. Se trata de pequeños caseríos, compuestos por una o varias habitaciones, y números variables de corrales y espacios de cultivo formalmente delimitados. Debido a que las estructuras de habitación y producción no suelen ser contiguas, estos asentamientos pueden extenderse sobre superficies considerables. El área estudiada comprende 11 de estos asentamientos, que designamos operativamente como Núcleos Residenciales Productivos Actuales (NRPA) (Figura 1). Concebimos a esta designación esencialmente como una categoría descriptiva espacial, que puede o no tener correlación directa con unidades sociales específicas (unidades domésticas, familias nuclea- 


\begin{tabular}{|c|c|c|c|c|c|}
\hline \multicolumn{2}{|c|}{ NRPA } & 1 & 2 & 3 & 4 \\
\hline \multirow{3}{*}{$\begin{array}{l}\text { Ubicación } \\
\text { (s/ Google Earth) }\end{array}$} & Latitud & $23^{\circ} 0^{\prime} 39.00^{\prime \prime}$ & $22^{\circ} 59^{\prime} 49.72^{\prime \prime}$ & $22^{\circ} 59^{\prime} 33.72^{\prime \prime}$ & $23^{\circ} 0^{\prime} 2.41^{\prime \prime}$ \\
\hline & Longitud & $65^{\circ} 21^{\prime} 30.96 "$ & $65^{\circ} 20^{\prime} 53.62^{\prime \prime}$ & $65^{\circ} 22^{\prime} 0.66^{\prime \prime}$ & $65^{\circ} 22^{\prime} 29.37^{\prime \prime}$ \\
\hline & Altura snm & 3470 & 3420 & 3426 & 3484 \\
\hline \multicolumn{2}{|c|}{ Número total de estructuras } & 18 & 9 & 5 & 11 \\
\hline \multicolumn{2}{|c|}{ Sup. construida total (m2) } & 1742 & 2141 & 608 & 2172 \\
\hline \multirow{4}{*}{$\begin{array}{l}\text { Espacio } \\
\text { techado }\end{array}$} & Nro. de estruct. & 9 & 4 & 2 & 5 \\
\hline & Sup. total (m2) & 296 & 83 & 167 & 169 \\
\hline & Planta & rect. & rect. & rect. & rect. \\
\hline & Promedio sup. & 32,8 & 20,75 & 83,5 & 33,8 \\
\hline \multirow{4}{*}{ Corrales } & Nro. de estruct. & 6 & 3 & 2 & 5 \\
\hline & Sup. total (m2) & 1137 & 851 & 174 & 1474 \\
\hline & Planta & rect./circular & rect./circular & rect. & rect./circular \\
\hline & Promedio sup. & 189,5 & 283,7 & 87 & 294,8 \\
\hline \multirow{4}{*}{$\begin{array}{l}\text { Espacios } \\
\text { agrícolas }\end{array}$} & Nro. de estruct. & 2 & 1 & 1 & 1 \\
\hline & Sup. total (m2) & 309 & 1207 & 267 & 529 \\
\hline & Planta & cuad./circular & irregular & rect. & rect. \\
\hline & Promedio sup. & 154,5 & 1207 & 267 & 529 \\
\hline $\begin{array}{l}\text { Estructuras } \\
\text { en desuso }\end{array}$ & Nro. de estruct. & 1 & 1 & & \\
\hline \multirow[t]{4}{*}{ Distancia (km) } & Vec. más cerc. & 1,85 & 1,39 & 1,2 & 0,9 \\
\hline & H. Yrigoyen & 7,09 & 2,04 & 2,4 & 3,36 \\
\hline & Humahuaca & 21,3 & 22,98 & 23,64 & 22,86 \\
\hline & Antumpa & 6,33 & 1,21 & 3 & 4,04 \\
\hline
\end{tabular}

Tabla 2. Características espaciales principales de los Núcleos Residenciales Productivos Actuales analizados en este trabajo (tabla continúa en la página siguiente).

res o familias extensas), concentrándonos fundamentalmente en describir sus características espaciales principales (Tabla 2). No podemos sobre la base sólo a imágenes satelitales, por otro lado, determinar si su ocupación es permanente o sólo estacional.

Los NRPA analizados se emplazan entre los 3.300 y $3.500 \mathrm{msnm}$ y son altamente variables en relación a las estructuras de habitación y productivas que los componen. Los NRPA más pequeños presentan superficies construidas que oscilan entre los 100-3.000 $\mathrm{m}^{2}$ (0,01 y 0,3 hectáreas) (Figura 2). Un segundo conjunto de NRPA muestra un mayor tamaño, oscilando en superficie construida entre 2 y 3 hectáreas (Figura 2). Se componen de dos o tres NRPA básicos, diferenciados espacialmente aunque muy próximos entre sí. Ambos tipos de NRPA podrían describirse también bajo las categorías arqueológicas tradicionales de "poblados dispersos" (Madrazo y Ottonello 1966:11-12), "aldeas" (Raffino 1977:257) o "trazados dispersos espontáneos” (Raffino 1991:81), aún a pesar de su reducido tamaño.

En términos productivos, aquellos NRPA ubicados en el curso del río Grande $(9,10$ y 11$)$ son los que presentan una 


\begin{tabular}{|c|c|c|c|c|c|c|}
\hline 5 & 6 & 7 & 8 & 9 & 10 & 11 \\
\hline $23^{\circ} 0^{\prime} 23.12 "$ & $22^{\circ} 59^{\prime} 44.95^{\prime \prime}$ & $22^{\circ} 58^{\prime} 13.46^{\prime \prime}$ & $22^{\circ} 58^{\prime} 27.73^{\prime \prime}$ & $22^{\circ} 59^{\prime} 29.51 "$ & $22^{\circ} 59^{\prime} 50.05^{\prime \prime}$ & $23^{\circ} 0^{\prime} 27.76^{\prime \prime}$ \\
\hline $65^{\circ} 22^{\prime} 51.30^{\prime \prime}$ & $65^{\circ} 22^{\prime} 58.47^{\prime \prime}$ & $65^{\circ} 23^{\prime} 33.71^{\prime \prime}$ & $65^{\circ} 24^{\prime} 00.77^{\prime \prime}$ & $65^{\circ} 20^{\prime} 9.68^{\prime \prime}$ & $65^{\circ} 20^{\prime} 0.98^{\prime \prime}$ & $65^{\circ} 19^{\prime} 46.87^{\prime \prime}$ \\
\hline 3501 & 3488 & 3515 & 3580 & 3347 & 3345 & 3315 \\
\hline 5 & 3 & 3 & 8 & 18 & 20 & 27 \\
\hline 217 & 308 & 171 & 628 & 2779 & 27724 & 24786 \\
\hline & 2 & 1 & & 3 & 3 & 9 \\
\hline 44 & 33 & 18 & & 103 & 105 & 143 \\
\hline rect. & rect. & rect. & & rect. & rect. & rect. \\
\hline 14,6 & 16,5 & 18 & & 34,3 & 35 & 15,9 \\
\hline & 1 & & 6 & 5 & 5 & 10 \\
\hline 173 & 275 & & 628 & 1356 & 939 & 699 \\
\hline circular & irregular & & rect. & rect. & rect./irregular & rect./irregular \\
\hline 86,5 & 275 & - & 104,7 & 271,2 & 187,8 & 69,9 \\
\hline & & 1 & & 1 & 1 & 6 \\
\hline & & 153 & & 1320 & 26680 & 23944 \\
\hline & & rect. [ & & rect. & irregular & irregular \\
\hline & & 153 & - & 1320 & 26680 & 23944 \\
\hline & & 1 & 2 & 9 & 11 & 2 \\
\hline 0.9 & 0,99 & 0,89 & 0,89 & 0,67 & 0,67 & 1,23 \\
\hline 4,8 & 3,61 & 4,17 & 4,86 & 2,32 & 3 & 6,4 \\
\hline 22,63 & 23,43 & 26,2 & 26,15 & 23,23 & 23,14 & 22,41 \\
\hline 4,19 & 4,66 & 6,18 & 6,71 & in situ & in situ & 0,8 \\
\hline
\end{tabular}

mayor superficie dedicada a cultivos formalmente definida, así como un mayor número de estructuras de habitación en uso y desuso (Tablas 1 y 2). Esto muestra que, independientemente de la demografia actual, esta es una ubicación favorable para el emplazamiento de instalaciones agrícolas y para la concentración de la población. Por el contrario, varios de los NRPA, emplazados a mayor altura en pequeñas quebradas más alejadas del río Grande, no poseen estructuras dedicadas al cultivo o bien las mismas son de pequeño tamaño. Los espacios relacionados con el pastoreo adquieren una mayor relevancia propor- cional en varios de estos casos, sugiriendo que es la actividad pastoril la que motiva o justifica la existencia de varios de estos asentamientos (Tabla 2).

Las entrevistas y observaciones realizadas muestran que algunos de los NRPA relevados tienen funciones complementarias entre sí, oficiando algunos de ellos de residencias más permanentes (en términos de la cantidad de tiempo que sus habitantes moran alli), mientras que otros, denominados "puestos", funcionan como satélites de aquellas, con ocupaciones breves (generalmente estacionales) y habitados por determinados miembros de la familia 




Figura 2. Histograma que muestra la distribución de los asentamientos analizados según la superficie construida de los mismos.

extensa para la realización de actividades específicas. De esta manera, en muchos casos los grupos familiares poseen más de una unidad residencial, con funciones económicas complementarias, aprovechando de manera eficiente la oferta ambiental que brindan los distintos escalones altitudinales característicos de la zona (Fabron 2016). Estudios actuales sobre actividades productivas agropastoriles en la Puna muestran semejanzas con las descriptas para nuestra zona de estudio (e.g. Bugallo y Tomasi 2012; Cladera 2013; Göbel 2002; González et al. 2013).

\section{Análisis de Vecino Más Cercano}

Para el caso de Negra Muerta, la dis- tancia promedio observada entre las viviendas es de $131 \mathrm{~m}$ y el valor obtenido por el Análisis de Vecino Más Cercano $(0,25)$ indica que la distribución espacial muestra una tendencia hacia el agrupamiento. En términos generales, esto suele resultar de múltiples factores relacionados con la existencia de algún tipo de atracción para que la población se concentre. En el caso de Negra Muerta es probable que el agrupamiento obedezca a la presencia de agua permanente y de tierras aptas para el cultivo en el fondo de la quebrada, aunque esto por sí sólo no explica por qué el agrupamiento poblacional se ha producido aquí y no en otras partes cercanas de la quebrada del río Grande que ofrecerian condiciones comparables. La ubicación de Negra 
Muerta sobre la antigua vía de comunicación que unía la Quebrada de Humahuaca con la Puna y el altiplano boliviano, antes de la construcción de la Ruta Nacional 9 y de la vía férrea, sin duda ha conferido al lugar un interés y valor decisivo a la hora de atraer población (ver Casanova 1933: 258). ${ }^{8}$

Por el contrario, en el caso de la ocupación dispersa, la distancia promedio observada entre los NRPA estudiados es de 1,07 $\mathrm{km}$ y el valor obtenido por el Análisis de Vecino Más Cercano $(0,91)$ es más indicativo de una distribución espacial aleatoria. Es decir, no hay factores que estimulen ni el agrupamiento ni la búsqueda de distancia entre los asentamientos. Por otra parte, la distancia promedio a la población de Hipólito Yrigoyen es de $4 \mathrm{~km}$, aunque con un rango estadístico amplio $(5,05 \mathrm{~km}$; oscilando entre $7,1 \mathrm{~km}$ y $2 \mathrm{~km}$ ). Es decir, no hay tampoco una distribución espacial homogénea con respecto al centro administrativo-comercial más importante de la zona, ni con respecto a Humahuaca, la población más grande en esta parte de la Quebrada de Humahuaca. Las vías de comunicación actuales (Ruta Nacional 9 y Provincial 13; FFCC General Belgrano) tampoco parecen influir decisivamente en la ubicación de estos asentamientos, que en buena medida parecen preceder a la existencia de las mismas.

\section{Paisajes productivos prehispánicos}

\section{Evidencias arqueológicas de agricultura prehispánica}

Empleando las imágenes satelitales y aéreas disponibles, complementadas con observaciones sobre el terreno, se buscaron rastros visibles de posibles estructuras agrícolas arqueológicas en el sector bajo estudio. Los conjuntos identificados se de- nominan operativamente aquí como Zonas Agrícolas Arqueológicas (ZAA). Identificamos seis de las mismas, que se distribuyen mayormente sobre la margen izquierda del río Grande, con una marcada concentración en el sitio arqueológico Antumpa (ZAA 1) (Figura 1). Resulta complejo discernir una cronología precisa de la construcción y uso de la mayor parte de estos restos, por lo que su descripción como un conjunto sincrónico prehispánico es sólo a los fines de obtener una caracterización general y comparar con la ocupación actual de la zona. A continuación se las describe brevemente.

ZAA 1: la concentración más densa de estructuras agrícolas arqueológicas se observa en el sitio Antumpa, que se ubica sobre un cono aluvial en la confluencia del arroyo Chaupi Rodeo y el río Grande. Los restos arqueológicos se extienden sobre un amplio faldeo, sobre una superficie total aproximada de 160 hectáreas, entre los 3.300 y 3.500 msnm (Figura 3). La parte más baja del sitio (sobre terrazas fluviales formadas entre comienzos del Holoceno y 500 años atrás [Cortés 2013]), presenta una densidad de vestigios mucho mayor, así como una ocupación post-hispánica más intensa (Leoni 2007, 2010). Las investigaciones han permitido determinar que una parte sustancial de la ocupación humana de Antumpa corresponde al período Formativo (ca. 3000 a.C.-1000 d.C.), aunque también hay presencia de materiales correspondientes a momentos posteriores (González 1977; Fernández Distel 1983; Hernández Llosas et al. 1983-85; Leoni 2007; Leoni et al. 2012, 2013).

Las estructuras agrícolas arqueológicas varian en su forma y tamaño, diferenciándose dos sectores bien definidos, separados por el borde de una antigua terraza pleistocénica que atraviesa Antumpa en dirección general norte-sur. Al oeste de esta terraza, en la parte más baja del sitio, se disponen amplias extensiones de estruc- 


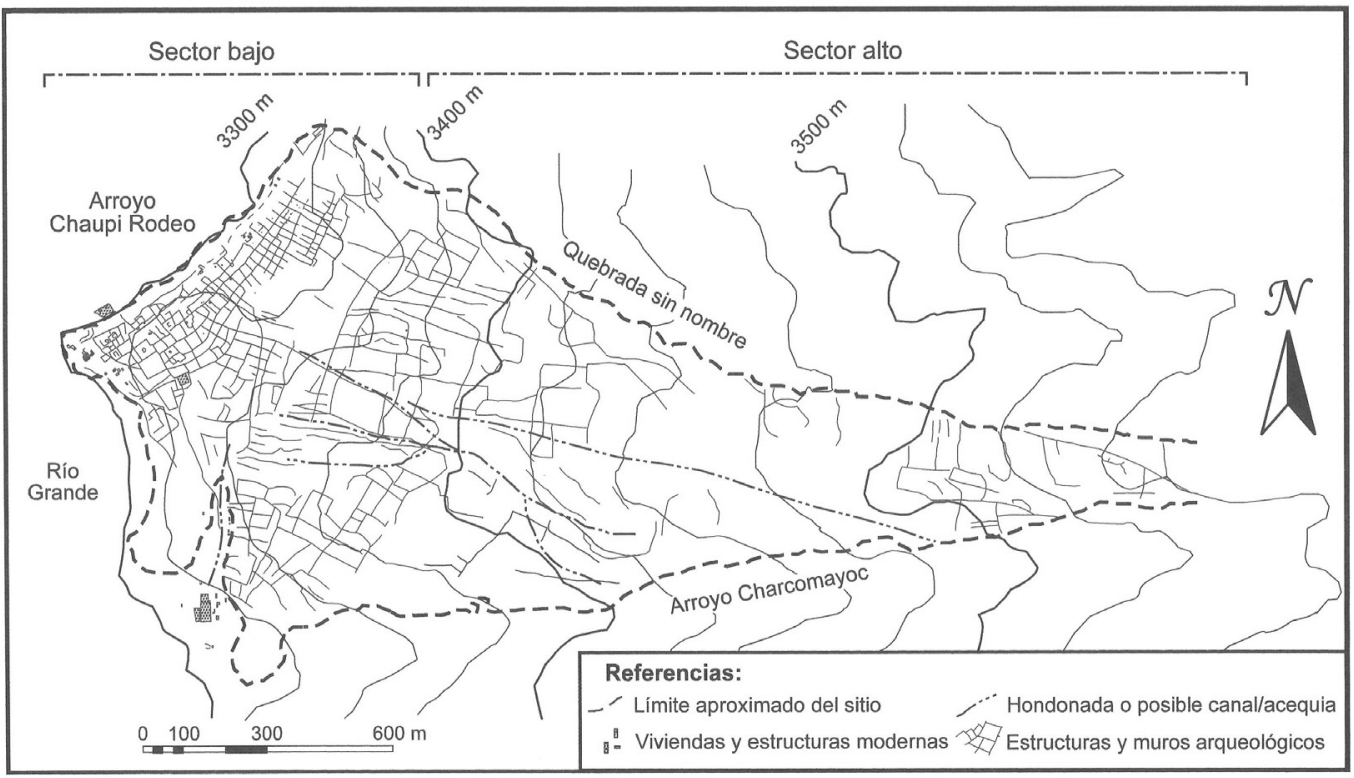

Figura 3. Plano del sitio arqueológico Antumpa, mostrando la distribución de las estructuras agrícolas arqueológicas mencionadas en el texto.

turas de forma cuadrangular, rectangular o trapezoidal, construidas de una manera bastante regular (Figura 3). Oscilan típicamente entre los 15 y $30 \mathrm{~m}$ de lado y sus paredes no muestran una construcción bien formalizada, consistiendo más bien en apilamientos lineales de rocas de gran tamaño antes que en pircas bien definidas. Estas estructuras se ajustan a lo que en literatura arqueológica suele denominarse "canchones de cultivo" (Albeck 1995: 260; Raffino 1975: Nota 8). En este sector, que tiene una superficie aproximada de unas 45 hectáreas, se concentraban también las áreas de habitación, representadas por recintos circulares y rectangulares, así como por montículos con sustanciales evidencias de ocupación prehispánica (Leoni 2007; Leoni et al. 2012, 2013).

En el sector ubicado hacia el este de la antigua terraza fluvial pleistocénica, a cotas por encima de los $3.350 \mathrm{msnm}$, las estructuras difieren notablemente. Predominan las de forma rectangular y cuadrangular, de entre 50 y 100 m de lado, mucho más irregulares en su diseño y construcción (Figura 3). Hay también algunas estructuras que presentan lados curvados, así como largas acumulaciones de piedras, dispuestas en sentido longitudinal a la pendiente. No se han detectado en este sector estructuras residenciales y el material arqueológico superficial es muy escaso. Como se ha señalado anteriormente (Leoni 2007), este sector podría reflejar un proceso de expansión del área agrícola original que nunca fue concluido completamente. Así, los cuadros de mayor tamaño podrian interpretarse como las estructuras básicas que luego se subdividirian. Las extensas acumulaciones lineales de piedras podrian constituir el primer paso en el despedre de las áreas elegidas para la construcción de las instalaciones agrícolas 
o bien las paredes troncales a partir de las cuales se construirian los cuadros o canchones de menor tamaño. Sin embargo, otra posibilidad que no debe descartarse es que el cultivo se haya desarrollado sin necesidad de espacios completamente formalizados. Situaciones como esta han sido reportadas, por ejemplo, en Pajchela, en la Puna jujeña, donde los espacios de cultivo sin pircado se identifican por su asociación con despedres (como podría ser en el caso de Antumpa) o canales de irrigación (Pey 2016: 70-71).

La secuencia de construcción y uso de estas instalaciones agrícolas en Antumpa permanece aún poco conocida. ${ }^{9}$ En efecto, su datación resulta compleja ya que, términos generales, no se observan grandes diferencias técnicas y constructivas entre los distintos conjuntos de espacios de cultivo. Posiblemente estos vestigios constituyan un palimpsesto resultante de la ocupación del lugar desde tiempos prehispánicos hasta el presente. Sin embargo, algunos aspectos nos llevan a pensar que al menos una parte sustancial de estas estructuras puedan haberse construido y utilizado durante el Formativo (ver Leoni 2007; Leoni et al. 2012, 2013). En efecto, su simplicidad constructiva y de diseño, notoria al compararlas con las instalaciones agrícolas de los Períodos de Desarrollos Regionales e Inca en la Quebrada de Humahuaca (Albeck 1992-93; Nielsen 1005) o en la Puna jujeña (e.g. Franco Salvi 2014; Pey 2016; Vaquer et al. 2014), así como su asociación directa con recintos y áreas de ocupación correspondientes al primer milenio d.C. (para las que se cuenta con varios fechados radicoarbónicos; ver Leoni et al. 2012, 2013), permiten suponer que el proceso de transformación del paisaje materializado en Antumpa se habria iniciado en esos momentos de la secuencia de ocupación. Sin embargo, es altamente probable que estas estructuras se hayan reutilizado y modificado con posterioridad, constituyendo los restos estáticos y abandonados que hoy vemos en Antumpa el reflejo de procesos dinámicos de diseño, construcción e imposición de múltiples paisajes agrarios en una amplia escala temporal.

ZAA 2: se trata de restos de posibles cuadros de cultivo y/o despedres que se ubican sobre la terraza fluvial en la margen izquierda del arroyo Chaupi Rodeo y el faldeo adyacente, entre el sitio Antumpa y el pequeño caserío actual de Vicientayoc. El estado de conservación de estas estructuras es pobre y presentan menor densidad y regularidad que las presentes en Antumpa, aunque probablemente se relacionaban directamente con las mismas, formando parte de un mismo conjunto.

ZAA 3: se trata de un conjunto de estructuras de gran tamaño y formas irregulares, ubicado en un sector alto y más o menos plano a $1,5 \mathrm{~km}$ al sur de la población de Hipólito Yrigoyen. Son visibles desde la Ruta Provincial 13 y han sido descritos por Alicia Fernández Distel (1997:330) como "extensos rectángulos para el cultivo y despiedrados de formato irregular", asignándoles una cronología correspondiente al Período Tardío. Estimamos su superficie en aproximadamente 23 hectáreas y no se encontraron restos materiales significativos (a excepción de un fragmento de pala litica y otro de molienda) asociados con estas estructuras, que están perturbadas y resultan poco discernibles sobre el terreno.

ZAA 4: se trata de restos dispersos, irregulares y mal preservados de despedres y/o canchones entre los arroyos Chaupi Rodeo y Moldes. Están ubicados sobre los faldeos por encima de las áreas de ocupación y agricultura actuales, en una zona de pendiente elevada.

ZAA 5: se trata de conjuntos de despedres $\mathrm{y} / \mathrm{o}$ canchones ubicados entre el arroyo Moldes y el extremo oeste de Negra Muerta. Ocupan faldeos elevados, por encima de las áreas de ocupación y agricultura actuales de Negra Muerta. Las imágenes 


\begin{tabular}{|l|r|r|}
\hline & Antumpa & Negra Muerta \\
\hline Promedio & 330 & 21185 \\
Máximo & 1367 & 96268 \\
Mínimo & 136 & 527 \\
Rango & 1231 & 95741 \\
Mediana & 244,5 & 14168 \\
Desv. Est. & 293,4 & 20874,5 \\
\hline
\end{tabular}

Tabla 3. Comparación estadística entre espacios de cultivo actuales de Negra Muerta y estructuras arqueológicas en Antumpa (medidas expresadas en $\mathrm{m}^{2}$ ). satelitales y la observación sobre el terreno han permitido identificar estructuras rectangulares de gran tamaño. A pesar de estar cerca de áreas pobladas actualmente, no se observa una reocupación significativa de estos espacios.

ZAA 6: posibles extensiones de cuadros de cultivo y/o despedres sobre la terraza fluvial en la margen izquierda del río Grande y pedemontes adyacentes, inmediatamente al sur de Antumpa. Las estructuras se encuentran perturbadas y no son fácilmente discernibles. ${ }^{10}$

\section{Comparación entre los paisajes agricolas prehispánico y actual}

De la información arriba presentada parece deducirse que el núcleo principal de la agricultura prehispánica en esta parte del sector del norte de la Quebrada de Humahuaca habría estado concentrado principalmente en la zona de Antumpa. Sin embargo, no puede descartarse que haya existido también una ocupación sustancial en donde se ubican actualmente los poblados de Negra Muerta e Hipólito Yrigoyen, aunque no se dispone hasta el momento de evidencias arqueológicas. Las mismas podrian haber quedado sepultadas bajo los espesos sedimentos aluviales del fondo de la quebrada o bajo la ocupación humana actual y subactual.

A partir de las entrevistas realizadas se pudo saber que la ocupación de Antum- pa en los últimos 70 años, por su parte, consistió en unas pocas familias asentadas sobre las terrazas del arroyo Chaupi Rodeo de más reciente formación (entre 500 y 100 años atrás [Cortés 2013]), despoblándose paulatinamente hasta mostrar el panorama de escasa ocupación que se observa actualmente. Los motivos del despoblamiento hasta el momento detectados incluyen una conjunción de factores sociales (migraciones por mejoras en la calidad de vida, pérdida de población por causas naturales) y factores geoambientales regionales (escasez de lluvias, procesos erosivos) (Fabron 2016).

En términos de estadística espacial e indices formalizados resulta dificil llevar a cabo una comparación específica entre las evidencias arqueológicas presentes en Antumpa y el paisaje productivo actual, dado lo fragmentario de la muestra arqueológica. Aún así, intentamos iniciar la comparación en dos aspectos básicos: 1) el tamaño de las parcelas productivas; 2) análisis del vecino más cercano. ${ }^{11}$

Con respecto al tamaño, los canchones arqueológicos en Antumpa, sobre todo los ubicados en el sector más bajo, destacan por ser mucho más pequeños que las áreas agrícolas formalmente delimitadas en el poblado actual de Negra Muerta. En efecto, las construcciones de uso agrícola arqueológicas analizadas en el sector noroeste del sitio $(n=16)$ muestran una superficie promedio muy por debajo del que presentan las área agrícolas formalmente delimitadas 




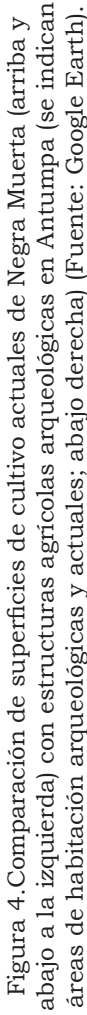


actuales en Negra Muerta (Tabla 3). Estas diferencias podrian encontrar su origen en la introducción de especies vegetales como el trigo y la alfalfa, con requerimientos distintos a las especies nativas, o de tecnología como el arado a tracción animal. Podrían vincularse también con la distinta disponibilidad de fuerza de trabajo y con diferencias en la organización social de la producción agrícola.

Sin embargo, es necesario aclarar que las áreas agrícolas actuales relevadas en Negra Muerta nunca son empleadas en su totalidad, sino que se suelen emplear parcelas mucho más reducidas dentro de ellas que no están formalmente delimitadas por pircas. La observación de las imágenes satelitales permite ver que estas parcelas se acercan más en su extensión a las estructuras agrícolas arqueológicas de Antumpa (Figura 4). La diferencia podría radicar, entonces, en que en el pasado se dedicaba un mayor esfuerzo a formalizar las parcelas trabajadas, más que a diferencias reales en las superficies totales cultivadas. Estas estructuras pueden haber cumplido funciones sociales y económicas importantes, tales como servir de marcadores de propiedad individual, familiar o comunitaria, o como organizadores de los regímenes de barbecho sectorial, a la manera de lo reportado por numerosos estudios etnográficos y arqueológicos (ver Erikson 2000, 2006; Guillet 1981). Así, las vastas extensiones de cuadros y líneas de piedras que cubren Antumpa podrían constituir los restos de lo que algún momento fuera la materialización en el espacio de una organización productiva, en la que se dividian las parcelas o chacras tanto por su pertenencia individual y grupal como por su lugar en un ciclo productivo cuidadosamente planificado de uso y reposo de la tierra.

En cuanto a la distribución espacial de las áreas de habitación arqueológicas, aplicamos el Análisis de Vecino Más Cercano al sector noroeste del sitio (Figura 4), con el propósito de comparar los valores obtenidos con los de la ocupación actual y subactual. Reconociendo que este análisis puede verse muy sesgado por la identificación parcial de los núcleos de ocupación arqueológicos (es decir, que pueden haberse dejado fuera áreas de ocupación aún no detectadas) y que se considera operativamente a todos estos núcleos como contemporáneos (aún cuando en varios de ellos aún resta por confirmarse su cronología exacta), el valor obtenido de 0,97 reflejaría una distribución espacial prácticamente aleatoria. Este es un valor muy lejano al obtenido para el poblado actual de Negra Muerta, que indicaba una mayor tendencia al agrupamiento, pero también del de 1,36 que se obtiene al analizar la distribución de las viviendas subactuales y actuales abandonadas en el mismo sector de Antumpa, indicativo de una distribución más homogéneamente espaciada, a lo largo del borde de la terraza del arroyo Chaupi Rodeo (Figura 4).

En relación a las restantes ZAA, se trata mayormente de restos de instalaciones de menor extensión y densidad que las presentes en Antumpa, con la excepción de la ZAA 3. La resolución de las imágenes satelitales, por otra parte, no permite identificar restos de recintos de habitación o viviendas individuales entre ellos, aunque es posible también que dependieran de asentamientos ubicados más cerca del fondo de quebrada, donde se encuentran las poblaciones actuales. Si bien no se ha podido estimar la superficie exacta que abarcan estos conjuntos de estructuras agrícolas, su uso en el pasado habría incrementado notablemente la superficie de cultivo total del área bajo estudio (asumiendo que las áreas agrícolas actuales también lo hayan sido en el pasado).

Hay ciertas características de emplazamiento y altitud que diferencian a las estructuras agrícolas arqueológicas identificadas de las actuales. En efecto, se ubican 
a mayor elevación, en torno a la cota de los $3.400 \mathrm{msnm}$. Esta situación plantea interrogantes en torno al funcionamiento del paisaje agrario pretérito en términos del uso de irrigación. En el caso mejor estudiado, Antumpa, no se han detectado aún evidencias de canales o estructuras relacionadas con el almacenamiento o distribución del agua. Si bien podrian haberse usado acequias y canales cavados en la tierra (similares a las que se emplean en la zona actualmente), dada la elevación relativa sobre la que se encuentran construidas las estructuras agrícolas resulta imposible derivar por gravedad agua de los cursos de agua (río Grande, arroyos Chaupi Rodeo y Charcomayoc) o de las surgentes naturales cercanas, que se encuentran a cotas inferiores. Algo similar se repite en las demás ZAA identificadas, siendo 1lamativamente evidente en la ZAA 3, donde por la topografía no existe posibilidad alguna de aprovechar por gravedad cursos de agua cercanos, permanentes o temporarios. Esta situación podría ser indicativa del uso generalizado del cultivo de secano o a temporal en el pasado, a diferencia de lo que ocurre en la actualidad en la zona (ver más abajo).

Finalmente, la comparación entre los paisajes productivos pasados y actuales no puede obviar la presencia de la ocupación dispersa, en la forma de los aquí denominados NRPA. No hay hasta el momento ninguna evidencia arqueológica de asentamientos comparables en el pasado, aunque si se han detectado ocupaciones temporarias y dedicadas a actividades específicas en cuevas y aleros en quebradas altas de acceso a la Puna (e.g. Inca Cueva Alero 1 [García 2015]; Huachichocana [Fernández Distel 1975]; Pintoscayoc 1 [Hernández Llosas 1998]), fuera del área de estudio aquí considerada, que se supone funcionaron complementariamente con los poblados ubicados a cotas más bajas en distintos momentos de la secuencia pre- hispánica. Aún cuando en el pasado prehispánico la mayor parte de la población hubiese estado asentada en lugares tales como Antumpa o Negra Muerta, no puede descartarse que hayan existido caserios menores comparables a los NRPA actuales aquí descritos. La ubicación de algunos de ellos en cotas de 3.400 msnm o mayores, podría responder a la integración de actividades pastoriles en el sistema productivo, pero también debe considerarse la posibilidad de la existencia de unidades sociales fisionadas o no integradas a los poblados mayores. Sin embargo, su detección arqueológica es dificultosa y como resultado las caracterizaciones de patrones de asentamiento prehispánicas suelen estar sesgadas en favor de los poblados de mucha mayor visibilidad. Asimismo, el uso de términos arqueológicos genéricos tales como "aldeas", "poblados dispersos" o "trazados dispersos espontáneos" (sensu Madrazo y Ottonello 1966; Raffino 1977, 1991) no parece constituir una caracterización espacial demasiado precisa en sí misma, si no va acompañada de formalizaciones, como las aquí ensayadas, en relación a la extensión, trazado interno, tamaño y forma de las estructuras, etc.

\section{Discusión: persistencias y rupturas en los paisajes productivos}

En base a lo presentado se pueden realizar las siguientes consideraciones generales acerca de las posibles similitudes y diferencias entre los paisajes productivos presentes y pasados. En primer término, el poblado de Negra Muerta concentra la mayor parte de la actividad agrícola y de la población actual en la zona estudiada, en torno a cotas que rondan los $3.300 \mathrm{msnm}$ y en directa relación con un curso de agua estable principal, el río Grande, que estructura linealmente la distribución espacial de viviendas y tierras de cultivo. El tipo de 
estructuras utilizada para el cultivo consiste en espacios de gran tamaño, acotados por muros, sin subdivisiones internas formalizadas y que no suelen ser sembrados en su totalidad en un mismo momento. El cultivo depende del riego, consistiendo la infraestructura hídrica fundamentalmente en acequias cavadas en la tierra a lo que se suma el empleo reciente de caños y mangueras (Fabron 2014, 2016). El cultivo "a temporal" o de secano es muy limitado en la actualidad en la zona bajo estudio, al igual que en la mayor parte de la Quebrada de Humahuaca (Albeck 1992-93: 62; Roisinblit et al. 2015: 9). ${ }^{12}$

Los registros históricos indican que el área del paraje Negra Muerta estuvo ocupada desde tiempos coloniales (Fandos 2014; Karasik 2008-09), presentando probablemente una distribución espacial similar a la que hoy se observa. Esto mostraria una continuidad general del asentamiento y la organización espacial productiva en una larga duración, aunque no necesariamente representaría un cuadro estático e inflexible, sino más bien lo que Tello (1999: 202) denomina una "persistencia a largo plazo de la morfología social del territorio"; morfología constituida por senderos, linderos de las parcelas, ubicación de las vivienda, que conforman una estructura paisajística temporalmente persistente. La mayor instancia reciente de alteración de este patrón la constituye la construcción de las nuevas vías de comunicación (FFCC y rutas) y de la población de Hipólito Yrigoyen, ya en el siglo XX. ${ }^{13}$ Como resultado de ello surgió una urbanización estandarizada, que sirve como nodo de comunicaciones ferroviarias y automotores, nuclea la actividad comercial, actúa como polo de concentración demográfica y alberga las instituciones estatales de distinto nivel. La presencia de esta población cambió, así, el foco y el eje del asentamiento en la zona, aunque no parece haber afectado substancialmente la estructura y organización espacial de las actividades productivas tradicionales.

La ocupación prolongada del paraje Negra Muerta hace pensar que esta zona podría haber ofrecido recursos para la instalación humana para lapsos temporales prehispánicos también. Sin embargo, no se han hallando hasta el momento vestigios arqueológicos significativos, aunque Lidia Garcia (2003: 27) ha mencionado la existencia una estructura arqueológica "en el centro de Negra Muerta" y nosotros hemos identificado restos de estructuras agrícolas en sus alrededores (ZAA 5; ver más arriba). Posiblemente, la combinación de una intensa reocupación del mismo espacio a través del tiempo y la dinámica actividad geomorfológica regional, haya obliterado los correlatos materiales previos, con lo cual la existencia de ocupaciones prehispánicas en este lugar sólo puede plantearse actualmente como de naturaleza puramente hipotética.

Es posible, sin embargo, establecer una comparación con los restos de un paisaje productivo prehispánico mejor preservado presentes en el cercano sitio arqueológico de Antumpa. Como se señaló, la ocupación prehispánica de Antumpa muestra algunos aspectos comparables a la actual de Negra Muerta en cuanto a la distribución de las áreas de vivienda, dispersas entre los campos de cultivo y no formando aglomeraciones destacables. Esto apuntaria a confirmar una continuidad y persistencia en la organización espacial del asentamiento y la producción de larga data. Sin embargo, la ocupación de Antumpa no persistió hasta el presente con la misma densidad y extensión que parece haber alcanzado en el pasado prehispánico. Podemos hipotetizar que una serie de causas de naturaleza sociocultural y ambiental confluyeron en esta instancia de discontinuidad en el paisaje local. En relación a las primeras, la drástica restructuración social y económica resultante del régimen colonial, así como la cercanía de Negra 
Muerta a las nuevas vías de comunicación, podrían haber llevado a la población a concentrase alli. Sobre las segundas, hay algunos indicadores interesantes.

En efecto, al examinar la distribución espacial de las instalaciones agrícolas prehispánicas se señaló que las mismas, tanto en Antumpa como en las demás ZAA, suelen ubicarse a cotas altitudinales mayores que las estructuras productivas actuales, en áreas donde el regadío por gravedad no es posible y que actualmente están despobladas y no incorporadas a la producción. Esto marca un interesante punto de discontinuidad en la conformación diacrónica de los paisajes productivos en una parte del sector norte de la Quebrada de Humahuaca. Podría ser el reflejo de cambios climáticos ocurrido en el pasado, tales como una reducción de las precipitaciones o cambios en el régimen estacional de las mismas, que hayan vuelto impracticable el cultivo de secano en estas áreas elevadas, obligando a la retracción de las superficies de producción.

Como se señaló más arriba, estudios geoambientales locales y regionales dan cuenta de cambios en la sedimentación y erosión en los últimos dos milenios y permiten plantear también la existencia de condiciones climáticas algo más favorables que las actuales, especialmente hace aproximadamente 2000 años (Cortés 2013; Fernández 1984; Kulemeyer 2005, 2013; Kulemeyer et al. 2015). Esto podría vincularse con la ocupación humana de Antumpa durante el primer milenio d.C. (período Formativo) y explicar el desarrollo de un gran paisaje productivo en ese lugar.

Para momentos posteriores, estudios paleoambientales realizados en la Puna jujeña han detectado evidencias vinculadas con la Anomalía Climática Medieval (ca. 800-1300 d.C.) y con la Pequeña Edad de Hielo (ca.1400-1800 d.C.) (Morales et al. 2009; Oxman et al. 2013). La primera se caracteriza por presentar un clima calu- roso y seco, que se relaciona en la Puna jujeña con cambios culturales tales como el agrupamiento de la población y la intensificación en el uso de plantas domésticas (Morales et al. 2009), en tanto en la Quebrada de Humahuaca coincide con un momento en el que se incrementan la complejidad sociopolitica y las situaciones de competencia intergrupal (Nielsen 2001). No se observan claramente indicadores de tales cambios en Antumpa u otros lugares de la zona bajo estudio para estos momentos, y no es claro aún si la significativa ocupación alcanzada durante el primer milenio d.C. continuó de la misma manera en estos momentos posteriores.

Con respecto a la Pequeña Edad de Hielo, estudios polínicos han detectado una fase húmeda (ca. 1500-1700 d.C.) y otra más seca (ca. 1700-1800 d.C.) en la Puna jujeña (Oxman et al. 2013: 385), que son coincidentes con las identificadas para el Área Andina Central (Liu et al. 2005). Resulta interesante que la primera fase coincidiría, en términos generales, con la expansión Inca a la Quebrada de Humahuaca (ca. 1430 d.C.), lo cual permitiría considerar que la expansión agrícola por ella generada (Nielsen 1995, 2001) se vio favorecida por el clima más benigno que imperaba en ese momento. Si bien en Antumpa no se han encontrado evidencias de una presencia Inca significativa (ver Fernández Distel 1983 para una descripción de estas evidencias), muy cerca del sitio se localizan las extensas instalaciones agrícolas de Rodero y Coctaca. Como se mencionó más arriba (ver también Leoni 2007, 2010), las estructuras observadas en el sector alto del sitio podrian evidenciar un intento, nunca concluido, de expandir los espacios de cultivo, como parte del masivo proceso de reorganización de la producción agrícola regional encarado por el estado Inca (Nielsen 1995: 250).

La fase seca de la Pequeña Edad de Hielo, por su parte, coincide con la instaura- 
ción del régimen colonial. Es posible pensar, entonces, que las formas de producir y la densidad demográfica en la zona se vieran afectadas tanto por este dramático cambio cultural, político y económico, como por factores climáticos y ambientales, que habrian limitado la práctica del cultivo sin riego en las áreas más elevadas de la zona. La introducción de una gran variedad de especies (vegetales y animales) alóctonas sin duda también impactó grandemente las características de la actividad productiva.

La existencia en la zona estudiada de restos de estructuras agrícolas en lugares deshabitados y donde hoy no se cultiva puede también interpretarse como el correlato de uno de esos momentos criticos en los paisajes productivos que Tello (1999: 206) denomina "de cambios boserupianos"14, en los cuales se busca ampliar la capacidad productiva del territorio mediante la extensión de las áreas cultivadas o la introducción de nuevas tecnologías. Esto puede obedecer tanto a desequilibrios demográficos como a la necesidad de responder a exigencias de instituciones políticas de nivel superior al de la comunidad campesina básica. Instancias de este tipo en la zona pueden haberse dado en el Período de Desarrollos Regionales (ca. 10001430 d.C.) con el desarrollo de entidades políticas del tipo señoríos, o con la incorporación de la región al estado incaico (ca. 1430-1536 d.C.), aunque resulta dificil pensar que esta supuesta ampliación de las áreas agrícolas hacia cotas más elevadas pueda haber prosperado en condiciones ambientales comparables a las actuales y limitaría dicha expansión a alguna de las fases húmedas que los estudios paleoambientales han logrado identificar.

Finalmente, existe una forma de ocupación actual mucho más dispersa y poco densa, representada por los asentamientos que aquí denominamos NRPA. Incluyen tanto pequeños caseríos permanentes ubicados junto al río Grande y con foco en la actividad agrícola, como puestos más vinculados con la actividad pastoril ubicados a cotas que rondan los $3.400 \mathrm{msnm}$ o superiores, que representarian complementos productivo-funcionales de las ocupaciones orientadas hacia la agricultura. Los NRPA ubicados en el fondo de la quebrada del río Grande representarian caseríos con orientación agrícola que no han dado origen a concentraciones mayores de población como la existente en Negra Muerta. Esto podría deberse a limitaciones geográfico-ambientales, tales como la ausencia de suficientes tierras aptas para la ampliación de los asentamientos y el cultivo. Pero también deben tenerse en cuenta cuestiones socioculturales y económicas, tales como la lejanía de vías de comunicación que actúan como atractores demográficos, o que esta ubicación resulte de una elección u obligación que hace que sus habitantes no quieran o puedan vivir en los lugares de mayor agregación. Otra posibilidad que debe investigarse histórica y etnográficamente es que se trate de desprendimientos o fisiones de unidades poblacionales mayores, resultado característico de procesos de crecimiento demográfico.

\section{Palabras finales}

Hemos abordado el análisis de los paisajes productivos del sector norte de la Quebrada de Humahuaca con una perspectiva que combina enfoques sincrónicos y diacrónicos, algo fundamental para comprender el desarrollo de la agricultura prehispánica y post-hispánica en esta zona. Lo visto hasta el momento permite enfatizar la centralidad de la práctica agrícola y visualizar algunas diferencias y similitudes entre los paisajes productivos del pasado y de la actualidad. En este sentido, hemos aquí dado los primeros pasos en el intento 
de desentrañar las distintas huellas tecnológicas, sociales y ambientales que han quedado materializadas en el complejo palimpsesto que observamos hoy en día, señalando algunas posibles instancias de continuidad y perduración así como otras de ruptura y cambio, y abriendo líneas de investigación de gran potencial.

\section{Agradecimientos}

Las investigaciones aquí presentadas se han llevado a cabo bajo un subsidio de la Agencia Nacional de Promoción Científica y Tecnológica (PICT 2005 Jóvenes Investigadores \#34424), continuándose en el marco del Proyecto de Investigación Plurianual (PIP)-CONICET 11220090100212 "Variaciones temporales en la ocupación humana del umbral entre tierras altas y bajas: arqueología de las nacientes de la Quebrada de Humahuaca" y del PIP-CONICET 11220130100094 "Arqueología y paisaje humano en Tres Cruces (Jujuy). Investigaciones en la convergencia geoambiental entre Puna, Quebrada de Humahuaca y Yungas", ambos dirigidos por la Dra. María Isabel Hernández Llosas. Finalmente, a los evaluadores por sus comentarios y sugerencias para mejorar el trabajo; sin embargo, cualquier error es pura responsabilidad de los autores.

\section{Notas}

1. Si bien el trabajo se basa principalmente en imágenes de sensores remotos, hemos procurado evitar superposiciones con áreas de estudio de otros investigadores.

2. Otras fuentes mencionan valores ligeramente superiores, alcanzando los $279 \mathrm{~mm}$ anuales (Combetto y da Veiga 1967, citados en Madrazo 1969).

3. La zona ecológica ubicada entre los 3.500 y $4.100 \mathrm{msnm}$ suele ser considerada como la zona de tubérculos y cereales indígenas por excelencia en diversas partes del Área Andina (Guillet 1981).

4. Forma local de referirse a la utilización de las lluvias estivales para irrigar los cultivos, también conocida como "a temporal" o de secano.

5. Mediante la aplicación de la fórmula: $\mathrm{R}=$ Fo/ Fe. Donde:

$\mathrm{R}$ : Vecino más cercano

Fo: Frecuencia observada o media observada entre vecinos más cercanos

Fe: Frecuencia esperada, que se calcula se calcula dividiendo $1 / 2$ por raíz cuadrada de $d$ (densidad de sitios en el área estudiada).

6. La población de Hipólito Irigoyen (o Iturbe) “(...) nació a partir de la instalación de la estación denominada Negra Muerta. El 27 de Agosto de 1947, se sancionó la Ley provincial $\mathrm{N}^{\circ} 1782$, por la cual se designó con el nombre de Iturbe al Pueblo y Jurisdicción del distrito 'Negra Muerta' (departamento de Humahuaca)" (Ferrari 2014: 104). La Comisión Municipal de Hipólito Yrigoyen, por su parte, se creó el 22 de abril de 1965 (http:/ /www.gobiernolocal. gov.ar/?q=taxonomy/term/14888; acceso marzo 2017)

7. Aunque cabe destacar que en la actualidad existe una pequeña ermita del "Señor de Quillaca" sobre la ruta nacional, donde se encuentra la única parada de transporte público en el paraje.

8. Dice Eduardo Casanova (1933:258): “(..) en los tiempos prehispánicos esta ruta fué mucho más importante que el otro camino [se refiere a la ruta del ferrocarril] (...) la decadencia completa de esta ruta, hoy desierta, no es de muchos años y los viajeros que han recorrido la región siempre hacen notar su existencia y antiguo esplendor.

9. En su análisis geoarqueológico de Antumpa, Cortés (2013) afirma con certeza que la mayor parte de las estructuras construidas sobre esta terraza pleistocénica corresponden al período Agroalfarero Tardío o de Desarrollos Regionales (ca. 1000-1430 d.C.). Si bien esto es factible, y de hecho hemos planteado en trabajos previos que podría corresponder a una ampliación de áreas de cultivo en momentos tardíos o Inca (e.g. Leoni 2007, 2010), no hay hasta el momento suficientes indicadores cronológicos (características constructivas, materiales arqueológicos en superficie, fechados radiocarbónicos) que permiten hacer unas adscripción temporal tan precisa como la que este autor postula.

10.Estas posibles instalaciones corresponderían al "Sector M" (comprendido entre Ro- 
dero e Iturbe) que identificó Albeck (199293: 67) en un trabajo previo. En este sector las superficies de cultivo prehispánicas se localizan sobre el pedemonte oriental por encima de los $3.300 \mathrm{msnm}$.

11. Cabe destacar que, como parte del análisis, se han contemplado otras variables, tales como la introducción de especies vegetales y animales, y herramientas de origen europeo, las cuales posiblemente también hayan influido en las modificaciones en las prácticas agropecuarias. No obstante, al haberse enfocado este trabajo en el uso de técnicas de observación remota y de análisis espacial, no se han empleado estas variables para esta comparación.

12. Sin embargo, su práctica es común en partes de la Puna jujeña como Yavi, donde la disponibilidad de agua para riego es menor, alcanzando hasta un $75 \%$ de la superficie productiva (Roisinblit et al. 2015: 9).

13. Aunque el trazado de la vía férrea sigue, en parte, el trazado del antiguo camino real (Ferrari 2014).

14. Por Esther Boserup, especialista en estudios de intensificación productiva.

\section{Bibliografia}

ACUTO, F.A. 2013. ¿Demasiados paisajes?: múltiples teorías o múltiples subjetividades en la arqueología del paisaje. Anuario de Arqueología (UNR) 5: 31-50.

ALBECK, M.E. 1992-93. Áreas agrícolas y densidad de ocupación prehispánica en la Quebrada de Humahuaca. Avances en Arqueología 2: 56-77.

ALBECK, M.E. 1995. Tecnología agrícola e hidráulica en Casabindo, prov. de Jujuy, Argentina. En Hombre y Desierto 9. Una perspectiva cultural. Actas del XIII Congreso Nacional de Arqueología Chilena, Antofagasta. Tomo I: Simposios, pp. 257-268. Antofagasta, Chile.

BALLESTEROS ARIAS, P. y F. CRIADO BOADO. 2009. El paisaje agrario medieval en Galicia. Herramientas metodológicas. En Poblament, territori i història rural. VI Congrés sobre Sistemes
Agraris, Organizació Social i Poder Local, editado por Jordi Bolòs y d’Enric Vicedo, pp. 599-612. Institut d’Etudis Llerdencs, Diputació de Lleida, Lleida.

BIANCHI, A. y C. YÁÑEZ. 1992. Las precipitaciones en el Noroeste Argentino (segunda edición). INTA Estación Experimental Agropecuaria Salta, Centro Regional, Salta - Jujuy.

BIDASECA, K. 2013. Relevamiento y sistematización de problemas de tierra de los agricultores familiares en la Argentina. Secretaría de Desarrollo Rural y Agricultura Familiar, Subsecretaría de Agricultura Familiar, Ministerio de Agricultura, Ganadería y Pesca, Buenos Aires.

BUGALLO, L. y J. TOMASI. 2012. Crianzas mutuas. El trato a los animales desde las concepciones de los pastores puneños (Jujuy, Argentina). Revista Española de Antropología Americana 42(1): 205-224

BUITRAGO, L.G. y M.T. LARRAN. 1994. El clima de la Provincia de Jujuy. Cátedra de Climatología y Fenología Agrícola, Facultad de Ciencias Agrarias, Universidad Nacional de Jujuy.

CASANOVA, E. 1933. Tres ruinas indigenas en quebrada de La Cueva. Anales del Museo Nacional de Historia Natural Bernardino Rivadavia 37: 255-319.

CLADERA, J.L. 2013. La Comunidad Indígena como categoría de traducción: trashumancia ganadera y propiedad jurídica en las sierras del Zenta (Departamentos de Humahuaca/Jujuy e Iruya/ Salta). En Espacialidades altoandinas. Nuevos aportes desde la Argentina, editado por A. Benedetti y J. Tomasi, pp. 257-300. Facultad de Filosofia y Letras, Universidad de Buenos Aires, Buenos Aires.

CORTÉS, R.G. 2013. Estudio geoarqueológico del yacimiento agroalfarero de Antumpa, Depto. Humahuaca, Jujuy, Argentina. Anuario de Arqueología (UNR) 
Leoni J. B. y Fabron G. - "Paisajes productivos actuales y pasados en el sector norte..."

5: 391-407.

CRIADO BOADO, F. 1991. Construcción social del espacio y reconstrucción arqueológica del paisaje. Boletín de Antropología Americana 24:5-29.

DAVID, B. y J. Thomas 2008. Landscape archaeology: introduction. En Handbook of Landscape Archaeology, editado por Bruno David and Julian Thomas, pp. 27-43. World Archaeological Congress, Left Coast Press, Walnut Creek CA.

EARLE, T. 1976. A nearest-neighbor analysis of two Formative settlement systems. En The Early Mesoamerican village, editado por K. Flannery, pp. 196-223. Academic Press, New York.

ERICKSON, C.L. 2000. The Lake Titicaca Basin: A pre-columbian built landscape. En Imperfect Balance: Landscape transformation in the Precolumbian Americas, editado por D. Lentz, pp. 311-356. Columbia University Press, New York.

ERICKSON, C.L. 2006. Intensification, Political Economy, and the Farming Community: In Defense of a Bottom-up Perspective of the Past. En Agricultural Strategies, editado por J. Marcus y C. Stanish, pp. 334-363. Cotsen Institute of Archaeology, University of California, Los Angeles.

FABRON, G. 2014. Producción agrícola tradicional en las nacientes de la quebrada de Humahuaca (Dpto. de Humahuaca, Jujuy, Argentina). La Zaranda de Ideas 10(1): 29-46.

FABRON, G. 2016. Investigaciones arqueológicas sobre las Formas de Organización de la Producción y Procesamiento Agricola y sus variaciones temporales en las nacientes de la Quebrada de Humahuaca en su intersección con la Puna (Provincia de Jujuy). Tesis Doctoral, Facultad de Filosofia y Letras, Universidad de Buenos Aires, Buenos Aires.

FANDOS, C.A. 2014. Enfiteutas, propieta- rios y arrendatarios en el departamento de Humahuaca Estructura social y distribución de la riqueza en la década de 1860. Estudios sociales del NOA 14: 41-61.

FORGIONE, C.A. 1982. Estudio antropológico cultural de la Sociedad Rural de la Quebrada de Humahuaca, provincia de Jujuy, República Argentina. Tesis Doctoral, Facultad de Filosofia y Letras, Universidad de Buenos Aires.

FERNÁNDEZ, J. 1984. Variaciones climáticas en la prepuna jujeña intervalo 5.000-2.000 años a.p. de interés para la arqueología. Anales del IANIGLA (Instituto Argentino de Nivología y Glaciologia) 6: 73-82.

FERNÁNDEZ DISTEL, A. 1975 Excavaciones arqueológicas en las cuevas de Huachichocana, departamento de Tumbaya, provincia de Jujuy, Argentina. Relaciones de Sociedad Argentina de Antropólogos VIII: 101-127.

FERNÁNDEZ DISTEL, A. 1983. Mapa arqueológico de Humahuaca. Scripta Ethnologica, Suplementa IV. Centro Argentino de Etnología Americana, Buenos Aires.

FERNÁNDEZ DISTEL, A. 1997. Diccionario arqueológico de Jujuy. Editorial Milor, Salta.

FERRARI, M. 2014. El ferrocarril a Bolivia. El proceso de poblamiento en las regiones de Puna, Quebrada de Humahuaca y Valles de la provincia de Jujuy. Revista Labor \& Engenho 8(1): 63-82.

FRANCO SALVI, V. 2014. Estudios preliminares sobre paisajes agrarios del Tardio en el área del San Juan Mayo (Provincia de Jujuy, Argentina). Comechingonia Virtual. Revista Electrónica de Arqueología VIII(2): 137-156.

GARCÎA, L.C. 2003. Azul Pampa en etapas productivas. Cuadernos FHyCS-UNJU 20: 5-35.

GARCÍA, L.C. 2015. El material lítico de Azul Pampa (Humahuaca, Jujuy, Ar- 
gentina) durante el bloque temporal 3000-1000 AP. Movilidad e Interacción. Relaciones de la Sociedad Argentina de Antropología XL(2): 395-423.

GÖBEL, B. 2002. La arquitectura del pastoreo: Uso del espacio y sistema de asentamientos en la Puna de Atacama (Susques). Estudios Atacameños 23: 53-76.

GOLOVANEVSKY, L. y A. RAMÍREZ. 2014 Población rural en Jujuy: dinámica, empleo y condiciones de vida según los censos de población del siglo XXI. III Jornadas Nacionales sobre estudios regionales y mercados de trabajo. Facultad de Ciencias Económicas y Unidad de Investigación en Comunicación, Cultura y Sociedad de la Facultad de Humanidades y Ciencias Sociales, Universidad Nacional de Jujuy y Red SIMEL, San Salvador de Jujuy. https://www. aacademica.org/iii.jornadas.nacionales.sobre.estudios.regionales.y.mercados.de.trabajo/38.pdf (Acceso mayo 2017).

GONZÁlEZ, A.R. 1977. Arte Precolombino de la Argentina. Introducción a su historia cultural. Filmediciones Valero, Buenos Aires.

GONZÁLEZ, N.M. 2011. Estructuras Prehispánicas y agricultura en la cuenca del Huasamayo (Tilcara-Jujuy). Relaciones de la Sociedad Argentina de Antropología XXXVI: 101-122.

GONZÁLEZ, N.; L. BERGESIO y L. GOLOVANEVSKY. 2013. La Feria Binacional de camélidos y las instituciones del desarrollo. Antipododa 18: 189-213.

GUILLET, D. 1981. Land tenure, ecological zone, and agricultural regime in the Central Andes. American Ethnologist 8(1): 139-156.

HERNÁNDEZ LLOSAS, M.I. 1998 Pintoscayoc: Arqueologia de quebradas altas. Tesis Doctoral, Universidad de Buenos Aires, Buenos Aires.

HERNÁNDEZ LLOSAS; M.I., S. RENARD
DE COQUET y M.M. PODESTÁ. 198385. Antumpa (Departamento Humahuaca, Provincia de Jujuy). Prospección, excavación exploratoria y fechado radiocarbónico. Cuadernos del INA 10: 525-531.

JOHNSON, G. 1977. Aspects of regional analysis in archaeology. Annual Review of Anthropology 6: 479-508.

KARASIK, G. 2008-09. Haciendas, campesinos y antropología: conflictos sociales y colonialidad en el extremo noroeste argentino en la primera mitad del siglo XX. Travesía. Revista de Historia Económica y Social 10-11: 197-223.

KULEMEYER, J. 2005. Holozäne Landschaftsentwicklung im Einzugsgebiet des Rio Yavi (Jujuy/Argentinien). Tesis Doctoral, Universität Bayreuth, Alemania.

KULEMEYER, J. 2013. Los cambios ambientales durante el Holoceno Superior en el norte argentino y su relevancia e interacción con la arqueología. Anuario de Arqueología (UNR) 5: 51-64.

KULEMEYER, J.; G. CORTÉS y L. LUPO. 2015. Cambios del paisaje durante el formativo en la región Andina del NOA y Chaco. En Crónicas materiales precolombinas. Arqueología de los primeros poblados del Noroeste Argentino, editado por A. Korstanje, M. Lazzari, M. Basile, F. Bugliani, V. Lema, L. Pereyra Domingorena y M. Quesada, pp. 465482. Sociedad Argentina de Antropología, Buenos Aires.

LEONI, J.B. 2007. Investigaciones arqueológicas en Antumpa y la Quebrada de Chaupi Rodeo (Depto. Humahuaca, Jujuy): contribuciones al estudio del período Temprano en el sector norte de la Quebrada de Humahuaca. Revista de la Escuela de Antropología (UNR) XIII: 183-196.

LEONI, J.B. 2010. Paisajes agrícolas en la Quebrada de Chaupi Rodeo: Antumpa y la agricultura prehispánica en el sector norte de la Quebrada de Humahua- 
Leoni J. B. y Fabron G. - "Paisajes productivos actuales y pasados en el sector norte..."

ca, Jujuy. Arqueología Rosarina Hoy 2: 91-113.

LEONI, J.B.; J. SARTORI; G. FABRON; A. HERNÁNDEZ y G. SCARAFIA. 2012. Aportes al conocimiento de las sociedades aldeanas del Período Temprano en la Quebrada de Humahuaca: una visión desde Antumpa. Intersecciones en Antropología 13: 17-131.

LEONI, J.B.; G. FABRON y A. HERNÁNDEZ. 2013. Antumpa, un paisaje productivo del primer milenio A.D. en el sector norte de la Quebrada de Humahuaca". Anuario de Arqueología (UNR) 5: 191-212.

LIU, K.B.; A.R. CARL y L.G. THOMPSON. 2005. Ice-core pollen record of climatic changes in the central Andes during the last 400 yr. Quaternary Research 64: 272-278.

MADRAZO, G.B. 1969. Reapertura de la investigación en Alfarcito (Pcia. de Jujuy, Rep. Argentina). Monografias $\mathrm{n}^{\circ} 4$, Museo Etnográfico Municipal "Dámaso Arce", Olavarría.

MADRAZO, G.B. y M. OTTONELLO. 1966. Tipos de instalación prehispánica en la región de la Puna y su borde. Monografias $\mathrm{N}^{\circ} 1$, Museo Etnográfico Municipal "Dámaso Arce", Olavarría.

MORALES M; R. BARBERENA; J.B. BELARDI; L. BORRERO; V. CORTEGOSO; V. DURÁN; A. GUERCI; R. GOÑI; A. GIL; G. NEME; H. YACOBACCIO y M. ZÁRATE. 2009. Reviewing human-environment interactions in arid regions of southern South America during the past 3000 years. Palaeogeography, Palaeoclimatology, Palaeoecology 281: 283-295.

NIELSEN, A.E. 1995. Aportes al estudio de la producción agrícola Inka en Quebrada de Humahuaca (Jujuy, Argentina). En Hombre y Desierto 9. Una perspectiva cultural. Actas del XIII Congreso $\mathrm{Na}$ cional de Arqueología Chilena, Antofagasta. Tomo I: Simposios, pp. 245-260.
Antofagasta, Chile.

NIELSEN, A.E. 2001. Evolución Social en la Quebrada de Humauaca (AD 7001536). En Historia Prehispánica Argentina. Tomo I, editado por E.E. Berberián y A.E. Nielsen, pp. 171-264. Editorial Brujas, Córdoba

OTTONELLO, M. y B. RUTHSATZ. 1986. Agricultura prehispánica y la comunidad, hoy en la Quebrada de Rachaite. Provincia de Jujuy, Argentina. Runa XVI: 1-27.

OXMAN, B.; H. YACOBACCIO; L. LUPO y P. TCHILINGUIRIAN. 2013. Primeros estudios paleoambientales en Lapao 2 (Puna Seca) y la señal de "Pequeña Edad del Hielo". Anuario de Arqueología (UNR) 5: 375-390.

PAOLI, H.P. 2003. Recursos Hídricos de la Puna, Valles y Bolsones Áridos del Noroeste Argentino. Aprovechamiento de los recursos hídricos y tecnología de riego en el altiplano argentino. INTA, Salta.

PEY, L. 2016. Donde convergen los rios. Una interpretación del paisaje agrícola de Casas Quemadas (quebrada de Pajchela, puna de Jujuy) durante el Periodo Tardio/Inka (ca. 1450-1536 años D.C.). Tesis de Licenciatura, Facultad de Filosofia y Letras, Universidad de Buenos Aires, Buenos Aires.

PINDER, D.; I. SHIMADA y D. GREGORY. 1979. The nearest neighbor statistic: archaeological application and new developments. American Antiquity 44(3): 430-445.

QUESADA, M. 2006. El diseño de las redes de riego y las escalas sociales de la producción agrícola en el 1er milenio DC (Tebenquiche Chico, Puna de Atacama). Estudios Atacameños 31: 31-46.

RAFFINO, R.A. 1975. Potencial ecológico y modelos económicos en el N.O. argentino. Relaciones de la Sociedad Argentina de Antropología, Nueva Serie IX: 21-45.

RAFFINO, R.A. 1977. Las aldeas del Formativo Inferior de la Quebrada del Toro. 
Libro del Centenario del Museo de La Plata. Tomo II, pp. 253-299. La Plata.

RAFFINO, R.A. 1991. Poblaciones Indigenas en Argentina: Urbanismo y Proceso Social Precolombino. Tipográfica Editora Argentina, Buenos Aires.

RINGUELET, R.A. 1961. Rasgos fundamentales de la zoogeografia argentina. Physis 22(63): 151-170.

ROISINBLIT, D.; C. GOLSBERG; J.H. SCHIMPF; G. FIGLIOLI; J. CHAUQUE; J. SARDINA; M. RIVERO; M.F. CHAVEZ; P. QUIROGA; S. ALVAREZ y V. HAMITY. 2015. La producción de quínua en la Quebrada de Humahuaca y Puna Jujeña. Trabajo presentado en el $\mathrm{V}^{\circ}$ Congreso Mundial y $\mathrm{II}^{\circ}$ Simposio Internacional de Granos Andinos, mayo de 2015, Jujuy, Argentina. http:/ /inta. gob.ar/sites/default/files / script-tmpinta_-_la_produccin_de_qunua_en_la_ quebrada_de_humahu.pdf (Acceso Julio 2017).

RUTHSATZ, B. y C.P. MOVIA. 1975. Relevamiento de las estepas andinas del noreste de la Provincia de Jujuy. Fundación para la Educación, la Ciencia y la Cultura, Buenos Aires.

STRANG, V. 2008. Uncommon ground: landscapes as social geography. En Handbook of Landscape Archaeology, editado por D. Bruno y J. Thomas, pp. 51-59. World Archaeological Congress, Left Coast Press, Walnut Creek CA.

TELLO, E. 1999. La formación histórica de los paisajes agrarios mediterráneos: una aproximación coevolutiva. Historia Agraria 19: 195-212.

VAQUER, J. M.; V. ZUCCARELLI; M. L. PEY y Y. CÁMERA. 2014. Paisajes agrícolas de la dominación y sus relaciones interregionales: el caso de Casas Quemadas (Cuenca superior del río San Juan Mayo, Jujuy, Argentina). En Desarrollos Regionales (1000-1500 DC) en el Sur de Bolivia y el Noroeste Argentino. Avances sobre la investigación arqueo- lógica, editado por María Beierlein de Gutiérrez y Daniel Gutiérrez, pp. 4763. Editorial La Pluma del Escribano, Tarija.

WILLEY, G.R. 1953. Prehistoric settlement patterns in the Virú Valley, Peru. Bureau of American Ethnology Bulletin 155, Smithsonian Institution, Washington D.C.

ZUCCARELLI, V.N. 2014. Primeras aproximaciones al paisaje agrario del Norte de la Sierra el Alto-Ancasti: un análisis multi-escalar. Arqueología 20(1): 115141. 